\title{
RhoC a new target for therapeutic vaccination against metastatic cancer
}

\author{
Lynn Wenandy • Rikke Bæk Sørensen • \\ Inge Marie Svane $\cdot$ Per thor Straten • \\ Mads Hald Andersen
}

Received: 29 January 2008 / Accepted: 29 March 2008 / Published online: 16 April 2008

(C) The Author(s) 2008

\begin{abstract}
Most cancer deaths are due to the development of metastases. Increased expression of $\mathrm{RhoC}$ is linked to enhanced metastatic potential in multiple cancers. Consequently, the RhoC protein is an attractive target for drug design. The clinical application of immunotherapy against cancer is rapidly moving forward in multiple areas, including the adoptive transfer of anti-tumor-reactive $\mathrm{T}$ cells and the use of "therapeutic" vaccines. The over-expression of RhoC in cancer and the fact that immune escape by down regulation or loss of expression of this protein would reduce the morbidity and mortality of cancer makes $\mathrm{RhoC} \mathrm{a}$ very attractive target for anti-cancer immunotherapy. Herein, we describe an HLA-A3 restricted epitope from RhoC, which is recognized by cytotoxic T cells. Moreover, RhoC-specific $\mathrm{T}$ cells show cytotoxic potential against HLA-matched cancer cells of different origin. Thus, RhoC may serve as an important and widely applicable target for anti-cancer immunotherapeutic strategies.
\end{abstract}

\section{Introduction}

There is consensus that cancer cells are antigenic since they express tumor-associated antigens that are recognized by autologous $\mathrm{T}$ cells. Several lines of evidence suggest that $\mathrm{T}$ cells are the main effectors in the immunological response against cancer cells [12]. Importantly, many T cell antigens are known to elicit spontaneous reactivity. More than 200

L. Wenandy · R. B. Sørensen · I. M. Svane · P. thor Straten ·

M. H. Andersen ( $\square)$

Center for Cancer Immune therapy (CCIT),

Department of Hematology, Herlev University Hospital,

2730 Herlev, Denmark

e-mail: mahaan01@heh.regionh.dk class I-restricted cytotoxic T-lymphocyte (CTL) peptide epitopes have been characterized, from highly diverse groups of proteins, e.g., Muc-1, telomerase, the MAGE proteins, NY-ESO-1, and p53, etc. [20]. Due to the phenomenon of "immune escape", in which antigen-negative cancer cells avoid immune recognition, strategies have been developed that conceptually focus on minimizing the risk of immune escape, by specifically targeting proteins that are important for the function, survival and growth of cancer cells [30]. Thus, it is well established that molecular events lead to the general cancer traits, e.g., the capacity to uncontrolled growth (abnormal cell cycle regulation), resistance to death (apoptosis resistance), the potential to migrate and grow at distant sites (metastasis), the capacity to induce new blood vessels (attract endothelial cells), and also the mechanisms involved in suppression of the immune system by cancer cells (secretion of immune-suppressive mediators), etc. [14]. The proteins or protein patterns responsible for these characteristics of cancer cells represent ideally suited target structures for therapeutic intervention, including immunological targeting. Importantly, these traits-molecular mechanisms aside-are essential characteristics of all life-threatening cancers, and therapies based on targeting of these characteristics molecularly are therefore broadly applicable to most if not all cancers. Several proteins responsible for or associated with these cancer traits have been characterized, which are targets for immunological recognition e.g., cell division (telomerase [31], survivin [4]), resistance to apoptosis (survivin, Bcl-2, Bcl-X(L), and Mcl-1 [1]), and tumor development (Cyp1B1 [18]). Recently, heparanase, a protein with metastasis promoting potential was described to be a target for $\mathrm{T}$ cells in cancer patients [29]. Generally, these targets represent broadly applicable vaccination targets in therapeutic vaccinations against cancer. Moreover, although vaccination against these proteins or groups of proteins is in itself a 
promising new approach to fight cancer, the combination with additional therapy could create a number of synergistic effects.

Rho GTPases affect several aspects of growth control, and cytoskeletal organization in response to extracellular factors [32]. Three Rho family members exist in humans; RhoA, B and C, which are highly homologous but with extensive heterogeneity in the C-terminal of the sequence. Although RhoB and RhoC were characterized at the same time as RhoA, they have received less attention because of their extensive homology to RhoA and because overexpression studies indicated that, like RhoA, they induced stress fibers in cells. More recent data suggests a more differential role in that RhoC has been shown to play an important role in metastasizing cancer cells [11]. Thus, several lines of evidence demonstrate a high expression of RhoC in cancer cells, and that the metastatic potential of cancer cells depends on expression of RhoC. Selective increased expression of RhoC has been described in metastatic cancers. Microarray analysis has shown that expression of RhoC is progressively increased as tumors become more aggressively metastatic and RhoC expression promotes metastasis [23, 33]. It has been demonstrated that loss of RhoC does not affect tumor development but decreases tumor cell motility and metastatic cell survival leading to a drastic inhibition of metastasis [13]. Interestingly, RhoC has not been found mutated in cancers, indicating that upregulated expression is sufficient to contribute to metastasis. In the present study, we examined whether RhoC is a target for cytotoxic $\mathrm{T}$ cells in patients with metastatic cancer.

\section{Materials and methods}

Patients

Peripheral blood lymphocytes (PBL) from HLA-A3+ cancer patients or peripheral blood mononuclear cells (PBMC) from healthy controls were obtained from the University Hospital Herlev, Denmark. The cancer patients included all had histological proven metastastic melanoma or renal cell carcinoma in progression. Generally, they were in a late disease stage with no further standard treatment options available. Cells were cryopreserved in FCS with $10 \%$ DMSO. Tissue typing was conducted at the Department of Clinical Immunology, The State Hospital, Copenhagen, Denmark. Informed consent was obtained from the patients before any of these measures.

RT-PCR for the detection of RhoC transcripts

RNA was extracted using the Purescript Isolation Kit (Gentra Systems Inc. MN, USA). In brief, $2-5 \mu \mathrm{g}$ of RNA were used in the synthesis of cDNA using the SuperScript II reverse transcriptase in a total volume of $50 \mu \mathrm{l} 1 \times$ buffer (Gibco-BRL, Life Technologies Inc., Gaithersburg, MD, USA) containing $10 \mathrm{mM}$ DTT. The RT reactions were primed with a mixture of oligo-dT and random hexamers, and incubations were performed at $37^{\circ} \mathrm{C}$ for $30 \mathrm{~min}, 42^{\circ} \mathrm{C}$ for $30 \mathrm{~min}$, and $72^{\circ} \mathrm{C}$ for $5 \mathrm{~min}$. Amplification was carried out with primers specific for RhoC (anti-sense: RhoC: $5^{\prime}$ cggggctagaaaacaatgc- $3^{\prime}$ ) together with a common sense primer $\left(5^{\prime}\right.$-ttttccatcgacagccetg- $\left.3^{\prime}\right)$. The size of the products is 477 bases. The following cancer cell lines were analyzed: the melanoma cell lines Est007 (FM3), Est027 (FM82), Est030 (FM9) (from the IPD-ESTDAB database, available at http://www.ebi.ac.uk/cgi-bin/ipd/estdab/ [22]), the head and neck cancer cell line CRL2095, the breast cancer cell line BT20, and the colon cancer cell line HT29 (from ATCC, available at http://www.ATCC.org).

Assembly assay for peptide binding to MHC class I molecules

The binding affinity of the synthetic peptides (Genscript, Scotch Plains, USA) to HLA-A3 molecules was measured by means of the assembly assay as previously described [8]. Briefly, T2-A3 cells were incubated in methionine-free RPMI 1640 (Gibco BRL, Paisley, UK) with 10\% dialysed FCS. Subsequently, cells were metabolically labeled with $50 \mu \mathrm{Ci}{ }^{35} \mathrm{~S}$-methionine (Amersham, Birkeroed, Denmark). Cell nuclei were removed by ultracentrifugation. Stably folded HLA molecules were immune-precipitated using the HLA class I-specific, conformation-dependent mAb W6/ 32. A-Sepharose beads were added to collect the folded MHC complexes and separated by isoelectric focusing gel electrophoresis. MHC heavy chains were quantified using the ImageGauge Phosphorimager program (FUJI Photo Film). The intensity of the band is directly related to the amount of peptide-bound class I MHC complex recovered during the assay. Subsequently, the extent of stabilization of HLA-A3 is directly related to the binding affinity of the added peptide.

Interferon- $\gamma($ IFN- $\gamma)$ ELISPOT assay

The ELISPOT assay was used to quantify peptide epitopespecific IFN- $\gamma$ releasing effector cells as described previously [5]. To extend the sensitivity of the ELISPOT assay, PBMCs were peptide stimulated $(10 \mu \mathrm{M})$ once in vitro. Next day, 40U/ml IL-2 (PeproTech, London, UK) was added. After 7 days, the cells were tested for reactivity. Briefly, nitrocellulose bottomed 96-well plates (MultiScreen MAIP N45; Millipore, Glostrup, Denmark) were coated with antiIFN- $\gamma$ Ab (1-D1 K; Mabtech, Nacka, Sweden). The wells were washed, blocked by X-vivo medium and the effector 
cells were added at different cell concentrations, with or without $10 \mu \mathrm{M}$ peptide (Rho1L2: RLGLQVRKNK; Rho1: RAGLQVRKNK) together with $10^{4} \mathrm{~T} 2-\mathrm{A} 3$ cells. The plates were incubated overnight. The following day, medium was discarded and the wells were washed prior to addition of biotinylated secondary Ab (7-B6-1-Biotin; Mabtech, Nacka, Sweden). The plates were incubated at room temperature (RT) for $2 \mathrm{~h}$, washed, and avidin-enzyme conjugate (APAvidin; Calbiochem/Invitrogen Life Technologies) was added to each well. Plates were incubated at RT for $1 \mathrm{~h}$ and the enzyme substrate NBT/BCIP (Invitrogen Life Technologies) was added to each well and incubated at RT for 5$10 \mathrm{~min}$. The reaction was terminated with tap-water upon the emergency of dark purple spots. The spots were counted using the ImmunoSpot ${ }^{\circledR}$ Series 2.0 Analyzer (CTL Analyzers, LLC, Cleveland, USA) and the peptide-specific CTL frequency could be calculated from the numbers of spotforming cells. The number of antigen-specific spots was calculated by subtracting the mean number of spots of the control wells from the mean number of spots in the positive wells; responses with a $P$ value $<0.05$ (Student's $t$ test for unpaired samples) were considered as positive. The definition is in respect with the CIMT Monitoring Panel inter-laboratory testing project (http://www.c-imt.org) [10].

\section{Dendritic cells}

Dendritic cells (DC) were generated from PBMC by adherence on culture dishes at $37^{\circ} \mathrm{C} / 5 \% \mathrm{CO}_{2}$ for $60 \mathrm{~min}$ in RPMI-1640 enriched with $10 \%$ human AB serum. Adherent monocytes were cultured in RPMI-1640 supplemented with $10 \%$ human $\mathrm{AB}$ serum in the presence of IL-4 (250 U/ $\mathrm{ml}$ ) and GM-CSF (1,000 U/ml) (Leucomax, Shering Plough, Farum, Denmark) for 6 days. DC were matured by addition of IL- $1 \beta(10 \mathrm{ng} / \mathrm{ml})$, IL-6 $(10 \mathrm{ng} / \mathrm{ml})$, TNF- $\alpha$ (10 ng/ml) (CellGenix, Freiburg, Germany), and $\mathrm{PGE}_{2}$ $(1 \mu \mathrm{g} / \mathrm{ml})$ (Pfizer, Brussels, Belgium).

Establishment of antigen-specific T cell cultures and clones

PBL from an untreated 65-year-old melanoma (MM) patient with multiple liver metastases, left pleural tumor, effusion, and osteolytic bone metastases were used for analyses. He had not received any treatment for his disease. PBL were stimulated with irradiated (20 Gy) autologous Rho1L2loaded DC (PBL:DC ratio $=3 \times 10^{6}: 3 \times 10^{5}$ ). The following day IL-7 $(5 \mathrm{ng} / \mathrm{ml})$ and IL-12 $(10 \mathrm{ng} / \mathrm{ml})$ (PeproTech, London, UK) were added. Stimulation of the cultures were carried out every 10 days with Rho1L2-loaded irradiated autologous DC $(2 \times)$ followed by Rho1L2-loaded irradiated autologous PBL $(3 \times)$. One hundred and twenty U/ml IL-2 (PeproTech, London, UK) was added after each stimulation. Growing cultures were tested for specificity for Rho1L2.
PBL from a specific culture were cloned by limiting dilution in the presence of cloning mix containing $10^{6} / \mathrm{ml}$ irradiated $(20 \mathrm{~Gy})$ lymphocytes from three healthy donors in X-vivo with $5 \%$ heat-inactivated human serum, $25 \mathrm{mM}$ HEPES buffer (GibcoBRL, Paisley, UK), and 120 U/ml IL-2 (PeproTech, London, UK). The plates were incubated at $37^{\circ} \mathrm{C} / 5 \% \mathrm{CO}_{2}$. Every $3-4$ days $50 \mu \mathrm{l}$ fresh media were added containing $120 \mu \mathrm{M} / \mathrm{ml}$ IL-2. Growing clones were expanded using cloning mix cells $\left(5 \times 10^{4}\right.$ cells/well $)$ and IL-2. After expansion the clones were tested for specificity and cytotoxic potential in a standard ${ }^{51} \mathrm{Cr}$-release assay.

\section{Cytotoxicity assay}

Conventional ${ }^{51} \mathrm{Cr}$-release assays for CTL-mediated cytotoxicity were carried out as described elsewhere [2]. Target cells were T2-A3 cells, the HLA-A3+ breast cancer cell line BT-20, the HLA-A3+ colon cancer cell line HT-29, the HLA-A3+ head and neck cancer cell line CRL-2095 (all available at the American Type Culture Collection (ATCC)), the HLA-A3+ melanoma cell line FM9, the HLA-A3- melanoma cell line FM82, and the HLA-A3+ melanoma cell line FM3 [15], with or without added HLA specific mAb W6/32 [7] ( $2 \mu \mathrm{g} / 100 \mu$ l [27]) or the HLA-A3 specific antibody GAPA3 [28].

\section{Results}

HLA-A3 binding peptides from RhoC

RhoC mainly differs from RhoA and RhoB in the C-terminal part of the sequence. Hence, this 20 amino acid region was scrutinized for putative HLA epitopes using the main HLA-specific anchor residues [6]. We identified a possible HLA-A3-restricted peptide Rho1 (RAGLQVRKNK). However, as Alanine is a poor anchor amino acid in position 2 this peptide was only expected to bind to HLA-A3 with low affinity. As many of the established $\mathrm{T}$ cell epitopes presented by cancer cells such as the melanoma antigens gp100 and MART-1 have relatively low binding affinities to the respective HLA class I molecules, it is common practice to generate heteroclitic peptides from such lowaffinity epitopes by substitution of amino acids at specific positions, i.e., the anchor positions, which are crucial for the binding of the peptide to the HLA molecule $[21,26]$. Consequently, we included a modified counterpart Rho1L2 (RLGLQVRKNK) in our studies, in which position 2 was modified from Alanine to Leucine. The two peptides were synthesized and examined for binding to HLA-A3 by comparison with the HLA-A3 high affinity positive control epitope from Influenza $\mathrm{NP}_{265-273}$ (ILRGSVAHK) by the assembly assay (data not shown). The modified Rho1L2 
peptide bound with intermediate affinity $\left(\mathrm{C}_{50^{-}}\right.$ value $\approx 4 \mu \mathrm{m})$, whereas the native peptide Rhol only bound very weakly to HLA-A3 $\left(\mathrm{C}_{50}\right.$-value $\left.>40 \mu \mathrm{m}\right)$ compared to a positive control peptide from Influenza $\mathrm{NP}_{265-273}$ $\left(\mathrm{C}_{50}\right.$-value $\left.\approx 0.5 \mu \mathrm{m}\right)$.

\section{Spontaneous T cell responses towards RhoC}

We scrutinized PBL from HLA-A3+ MM and renal cell carcinoma (RCC) patients for the presence of specific $\mathrm{T}$ cell responses against the modified Rho1L2 (RLGLQVRKNK) peptide by means of the IFN- $\gamma$ ELISPOT secretion assay. As depicted in Fig. 1, specific T cell responses were present among PBL of three out of ten MM patients. However, we could not detect a response against the very weak HLA-A3binding native peptide in these patients (data not shown). Likewise, no responses were detected in either RCC patients or healthy controls (HD) against either Rho1L2 or Rho1.

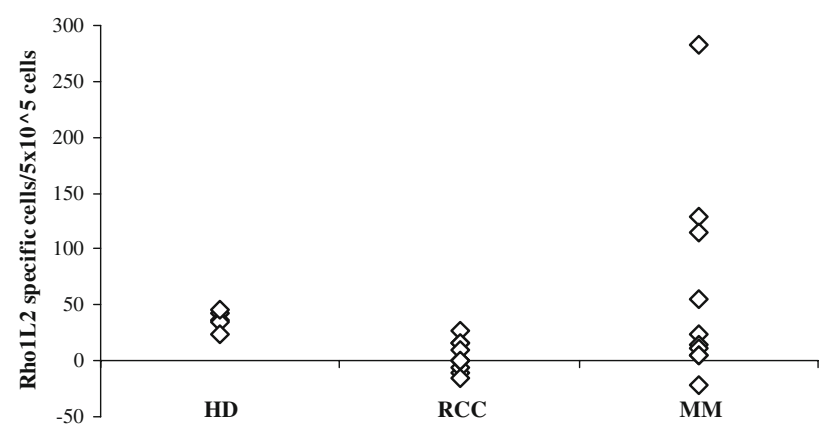

Fig. 1 HLA-A3 restricted T-cell responses against Rho1L2 as measured by IFN- $\gamma$ ELISPOT The average number of peptide specific IFN $-\gamma$ spots formed in response to Rho1L2 among $5 \times 10^{5}$ in vitro stimulated PBMC from five HLA-A3+ healthy donors $(H D)$, PBL from ten renal cell carcinoma patients $(R C C)$, and ten melanoma patients $(M M)$. Measurements were made in triplicates

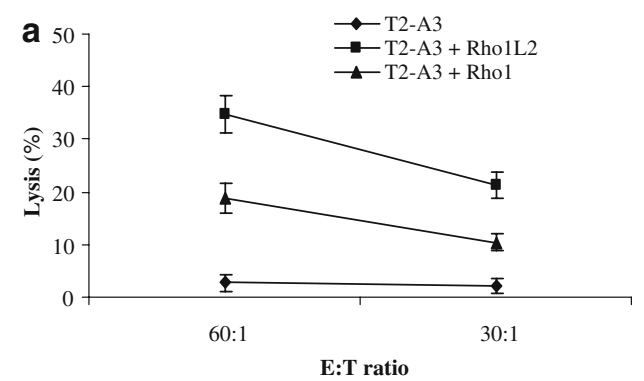

Fig. 2 T cell antigen specificity and cross reactivity. a Cytotoxicity by ${ }^{51}$ Cr-release assay of a bulk culture stimulated with Rho1L2-loaded autologous DC/autologous PBL. Specific lysis of T2-A3 cells with no peptide or pulsed with Rho1L2 $(10 \mu \mathrm{M})$ or Rho1 $(10 \mu \mathrm{M})$. E:T ratio = 60:1, 30:1. b Specificity of a $\mathrm{T}$ cell clone (clone 9 ) assayed by ${ }^{51} \mathrm{Cr}-$ release assay. Lysis of T2-A3 cells with no peptide, pulsed with
T cell antigen specificity and Rho1/Rho1L2 cross-reactivity

Having identified patients hosting responses against the Rho1L2 peptide, we used PBL from these cancer patients to generate CTL bulk cultures against this peptide in vitro. Subsequently, we in vitro stimulated PBL from such a patient with Rho1L2-pulsed autologous DC. After five in vitro restimulations, the peptide specificity was tested in standard ${ }^{51} \mathrm{Cr}$ release assays using $\mathrm{T} 2-\mathrm{A} 3$ cells without peptide or loaded with Rho1 $(10 \mu \mathrm{M})$ or Rho1L2 $(10 \mu \mathrm{M})$ as target cells (Fig. 2a). This assay revealed that the bulk cultures lysed both T2-A3 cells pulsed with Rho1L2 and Rho1 efficiently, whereas no cytotoxicity was observed against unpulsed T2-A3 cells.

Next, CTL clones were established from the specific $\mathrm{T}$ cell cultures by limiting dilution. After a short expansion step, the specificity of the growing clones was analyzed in standard ${ }^{51} \mathrm{Cr}$ release assays. Four RhoC-specific $\mathrm{T}$ cell clones were generated, and one of these was selected for further expansion as it had the highest growth rate (\# clone 9). Clone 9 effectively lysed T2-A3 cells pulsed with both the modified Rho1L2 and the native Rho1 peptide underlining that Rho1L2 specific T cells cross react with the native analog peptide (Fig. 2b). To examine the HLA restriction of clone 9, we tested the effect of blocking HLA-class I by addition of the HLA specific mAb W6/32 and the HLA-A3 specific mAb GAP A3. Lysis could be completely blocked by incubation of the target cells with both antibodies (Fig. 2b).

\section{Capacity of RhoC-specific T cells to kill tumor cells}

We examined RhoC expression in cancer cells of different origin by RT-PCR. All cancer cell lines examined expressed RhoC (Fig. 3). Next, we examined the Rho1L2/Rho1 specific bulk cultures capacity to kill RhoC+ melanoma cells.

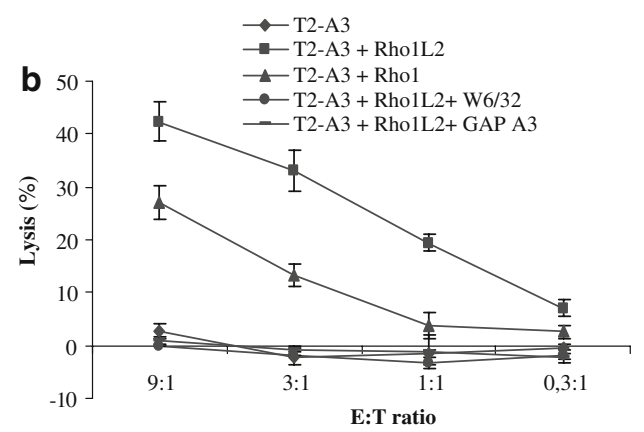

Rho1L2 $(10 \mu \mathrm{M})$, Rho1 $(10 \mu \mathrm{M})$ and of Rho1L2-pulsed T2-A3 cells with addition of the HLA-class I specific antibody W6/32 or HLA-A3 specific antibody GAP A3 at different E:T ratios $(9: 1 ; 3: 1 ; 1: 1 ; 0,3: 1)$. All measurements were made in duplicates. Error bars indicate the standard deviation 


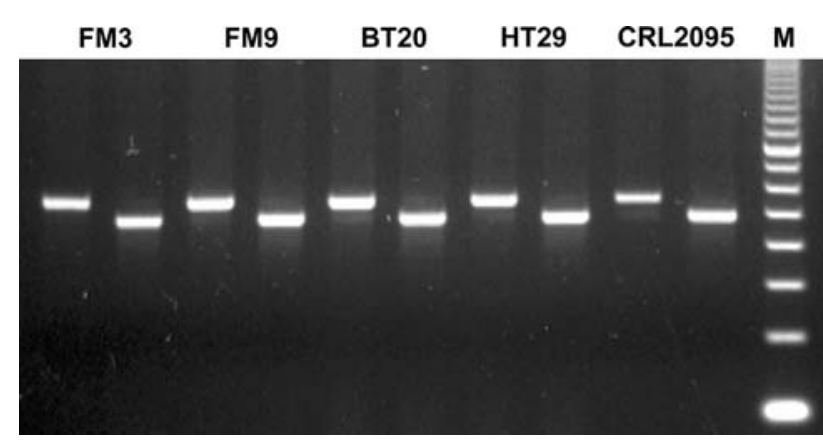

Fig. 3 PCR products electrophoresed in agarose gel and stained with EtBr. The image represents five different cancer cell lines, all being positive for RhoC. For each cancer cell line the left band represents GAPDH and the right band represents RhoC

To this end, the HLA-A3+ FM3 melanoma cells were killed with high efficacy in a HLA-restricted matter as lysis could be completely blocked by incubation of FM3 target cells with W6/32 (Fig. 4a).

Likewise clone 9 generated from the specific bulk culture was able to kill FM3 melanoma cells (Fig. 4b). A second experiment confirmed the aforementioned results (Fig. 4c). The addition of cold (unlabeled) T2-A3 cells pulsed with the Rho1L2 $(10 \mu \mathrm{M})$ peptide completely abrogated the killing of FM3 melanoma cells (Fig. 4b, c). Moreover, the RhoCspecific CTL clone was able to lyse the HLA-A3+ melanoma cancer cell line FM9. As an additional control, we
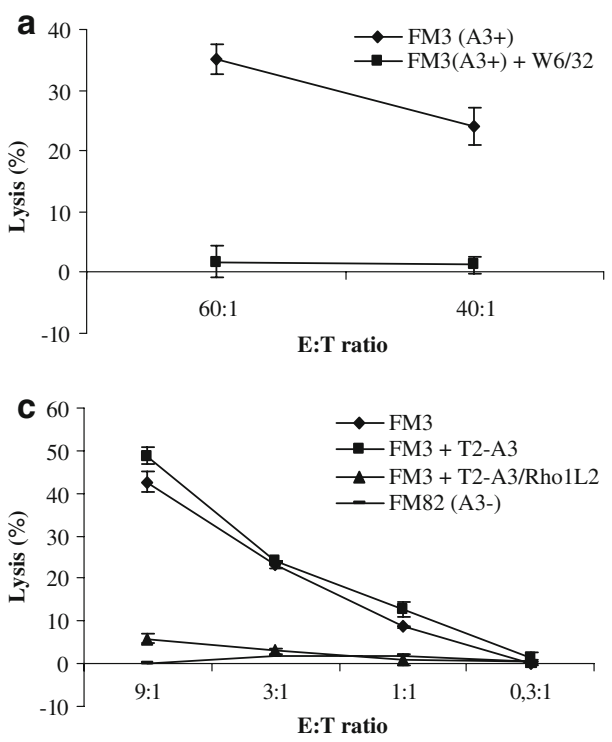

Fig. 4 Functional capacity of RhoC-specific T cells. a Cytotoxicity of a bulk culture stimulated with Rho1L2-loaded autologous DC/autologous PBL. Specific lysis of the HLA-A3+ melanoma cell line FM3 without and with the addition of the HLA-class I specific antibody W6/ 32. E:T ratio $=60: 1,40: 1$. b Lysis by a Rho1L2-specific clone (clone 9) of the HLA-A3+ melanoma cell line FM3, cell lysis with addition of unlabeled T2-A3 cells pulsed with Rho1L2 $(10 \mu \mathrm{M})$ or no peptide (inhibitor to target ratio $=20: 1$ ), and cell lysis of the HLA-A3+ mela- used the HLA-A3- melanoma cell line FM82 as target cells. No cytotoxicity was observed against this cell line.

As the expression of RhoC in metastatic cancer has been described in cancers of different origin we further examined the RhoC specific CTL clone capacity to kill other cancer cells than melanoma (Fig. 4d). Subsequently, the HLAA3+ breast cancer cell line BT-20, the HLA-A3+ head and neck cancer cell line CRL-2095 and the HLA-A3+ colon cell line HT-29 were used as target cells. The RhoC-specific CTL clone lysed all HLA-A3+ cell lines, although the colon cell line HT-29 only to a limited extent.

\section{Discussion}

RhoC has been identified as an especially important player in metastasis [11, 13], and its expression correlates with metastatic spread of various types of carcinomas [16, 17]. Ideal targets for immunotherapy are gene products silenced in normal tissues but over-expressed in cancer cells, and directly involved in tumor cell survival and progression. Metastasis is the culmination of neoplastic progression. The important role of a given protein in the process of metastasizing implies that immune escape by down regulation or loss of expression of this protein would reduce the morbidity and mortality of cancer. These characteristics highlight RhoC as a very attractive target for immunotherapy of
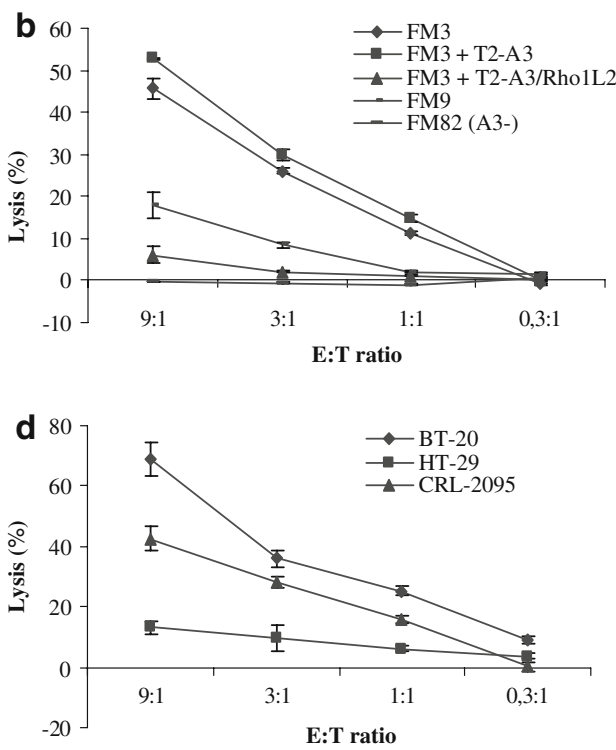

noma cell line FM9 and the HLA-A3- melanoma cell line FM82. Measurements were made in duplicates for all E:T ratios. $\mathbf{c}$ Repetition of the experiments shown in b) (without inclusion of FM9). d Lysis by a Rho1L2-specific clone of the HLA-A3+ breast cancer cell line BT-20, colon cancer cell line HT-29 and head and neck cancer cell line CRL2095. All measurements were made in duplicates. Error bars indicate the standard deviation 
cancer. Furthermore, since selective increased expression of RhoC has been described in metastatic cancers, the introduction of $\mathrm{T}$ cell tolerance against $\mathrm{RhoC}$ might be less problematic compared to tumor antigens, which are expressed in the primary tumor at high levels.

To sustain the hypothesis of RhoC as a broadly expressed $\mathrm{T}$ cell target we initially followed a 'reverse immunology' approach. We scanned the C-terminal region of the RhoC protein for the presence of HLA-A3 peptide binding motifs and used these to search for specific $\mathrm{T}$ cell responses in cancer patients. To this end, we were able to detect spontaneous HLA-A3-restricted CTL responses against a modified RhoC peptide epitope by means of ELISPOT in PBL from melanoma patients. No responses against this modified epitope were detected in any healthy controls. However, we could not detect a response in the ELISPOT against the native low-affinity binding peptide in PBL from neither cancer patients nor healthy controls. It has previously been described that it is possible to measure spontaneous $\mathrm{T}$ cell responses against modified peptides in PBL of cancer patients by the ELISPOT without detectable responses against the native analogs. This is largely due to technical reasons, e.g., stabilization of sufficient amounts of class I molecules on the surface of the T2 cells [3, 9]. A better place to look for specific $\mathrm{T}$ cells would be in the inflammatory infiltrate of the tumor or in the bone marrow. With regard to the latter, Sommerfeldt and colleagues show very strong $\mathrm{T}$ cell responses against heparanase in the bone marrow of cancer patients [29].

The use of modified peptides with improved HLA binding affinities has previously been demonstrated to be suitable for induction of CTL responses [25]. It is, however, still critical to establish that Rho1L2-specific CTL also react against the native Rhol peptide. Hence, a critical issue in the reverse immunology strategy for CD8 $\mathrm{T}$ cell target antigen identification is clearly to demonstrate that the peptide is processed and naturally presented on the surface of tumor cells. In order to do so we in vitro stimulated PBL from a responding patient with the Rho1L2 peptide and showed that the resulting culture was able to kill not only target cells pulsed with the modified peptide, but in addition both target cells pulsed with the native peptide and melanoma cells. To further clarify this point, we cloned RhoC-specific $\mathrm{T}$ cells and examined the specificity and immunogenicity of such CD8 T cells. The Rho1L2 specific clone not only killed target cells pulsed with the modified peptide Rho1L2 but in addition recognized the native Rho1 peptide in an antigen specific and HLA-A3-restricted manner. Furthermore, it effectively killed cancer cell lines of different origin in a HLA-restricted manner. Consequently, the presentation of the Rho1 peptide in context of HLA-A3 molecules on the tumor cells is necessary for the efficient lysis of target cells. The killing of tumor cells of different origin underlines the universal characteristics of RhoC. The HLA-A3 restriction of the clone was confirmed using monoclonal antibodies and cold target cells (peptide pulsed T2-A3 cells), which completely abrogated killing of tumor cells. Any potential correlation between CTL lysis and RhoC expression would be extremely revealing especially since microarray analysis has shown that expression of RhoC in vivo is progressively increased as tumors become more aggressively metastatic. We could, however, not detect a direct correlation between RhoC expression and lysis as the RhoC expression in the cell line HT-29 (which is relatively poorly killed by the RhoC-specific $\mathrm{T}$ cells) is as high as in any of the other lines. In this regard, it should be noted that many factors contribute to the killing (or lack of killing) of target cells by cytotoxic $\mathrm{T}$ cells, including $\mathrm{T}$ cell avidity, expression of HLA on the surface of the target cells as well as inhibitory and/or activating co-receptors.

RhoA, RhoB, and RhoC are highly homogeneous sharing $85 \%$ amino acid sequence. As we wanted to examine the $\mathrm{T}$ cell reactivity against $\mathrm{RhoC}$ we examined the C-terminal region of $\mathrm{RhoC}$ as this region completely differs from RhoA and RhoB (no homology). However, this region only includes around 20 amino acids, which implies that it might not include peptide epitopes restricted to all class I and/or II alleles. Naturally, there might be other regions of RhoC from which there are derived peptides that are recognized by $\mathrm{T}$ cells. Such $\mathrm{T}$ cells might, however, in addition recognize RhoA and RhoB derived peptides. Consequently, a potential anti-cancer response directed against such peptides could lead to a response against the non-relevant proteins RhoA and especially RhoB. However, although the main concern in anti-cancer immune therapy is severe autoimmunity, it only represents one side of the story. Another important aspect is the fact that a $\mathrm{T}$ cell response against peptides from other regions of $\mathrm{RhoC}$ would be opposed by mechanisms regulating and suppressing immunity against RhoA and RhoB. Thus, $\mathrm{T}$ cell tolerance caused by crossreactivity with RhoA and RhoB could reduce the anticancer response.

Harnessing of the immune system for the battle against cancer has been the focus of tremendous research efforts over the past two decades. Multiple means to achieve this goal have been investigated, including adoptive transfer of anti-tumor-reactive $\mathrm{T}$ cells, and systemic or localized administration of immune modulating cytokines. Clinical vaccination trials using tumor-associated antigen-derived peptides are presently ongoing and although most cancer patients included in current vaccination trials are end-stage patients, vaccination has repeatedly been shown to be capable of induction of anti-tumor CTL responses [19, 24]. Still, the clinical benefit for the treated patients is only marginal. We believe that induction of powerful $\mathrm{T}$ cell responses against RhoC, e.g., by therapeutic vaccination, may offer a 
new mean to target metastatic cancer cells. This would be particularly attractive after surgery of the primary tumor as selective increased expression of RhoC has been described in metastatic cancers. Naturally this needs to be verified, e.g., by the use of animal studies, to determine vaccination time, dose and indication(s) before moving into the clinic.

Acknowledgments We would like to thank Merete Jonassen for excellent technical assistance. We further extend our thanks to all the patients who donated blood to perform these studies. This study was supported by grants from the Danish Medical Research Council, The Novo Nordisk Foundation, The Danish Cancer Society, The John and Birthe Meyer Foundation, Herlev Hospital, BFR04/097 fellowship (Ministry of Culture, Higher Education and Research, Luxembourg) and Lions, Vaincre le Cancer, Luxembourg.

Open Access This article is distributed under the terms of the Creative Commons Attribution Noncommercial License which permits any noncommercial use, distribution, and reproduction in any medium, provided the original author(s) and source are credited.

\section{References}

1. Andersen MH, Becker JC, Straten P (2005) Regulators of apoptosis: suitable targets for immune therapy of cancer. Nat Rev Drug Discov 4:399-409

2. Andersen MH, Bonfill JE, Neisig A, Arsequell G, Sondergaard I, Valencia G, Neefjes J, Zeuthen J, Elliott T, Haurum JS (1999) Phosphorylated peptides can be transported by tap molecules, presented by class I MHC molecules, and recognized by phosphopeptide-specific CTL. J Immunol 163:3812-3818

3. Andersen MH, Pedersen LO, Becker JC, thor Straten P (2001) Identification of a cytotoxic $\mathrm{T}$ lymphocyte response to the apoptose inhibitor protein survivin in cancer patients. Cancer Res 61:869-872

4. Andersen MH, Pedersen LO, Capeller B, Brocker EB, Becker JC, thor Straten P (2001) Spontaneous cytotoxic T-cell responses against survivin-derived MHC class I-restricted T-cell epitopes in situ as well as ex vivo in cancer patients. Cancer Res 61:5964-5968

5. Andersen MH, Svane IM, Kvistborg P, Nielsen OJ, Balslev E, Reker S, Becker JC, Thor SP (2005) Immunogenicity of Bcl-2 in cancer patients. Blood 15:728-734

6. Andersen MH, Tan L, Sondergaard I, Zeuthen J, Elliott T, Haurum JS (2000) Poor correspondence between predicted and experimental binding of peptides to class I MHC molecules. Tissue Antigens 55:519-531

7. Barnstable CJ, Bodmer WF, Brown G, Galfre G, Milstein C, Williams AF, Ziegler A (1978) Production of monoclonal antibodies to group-A erythrocytes, Hla and other human cell-surface antigens-new tools for genetic-analysis. Cell 14:9-20

8. Berke Z, Andersen MH, Pedersen M, Fugger L, Zeuthen J, Haurum JS (2000) Peptides spanning the junctional region of both the $a b l / b c r$ and the bcr/abl fusion proteins bind common HLA class I molecules. Leukemia 14:419-426

9. Bristol JA, Schlom J, Abrams SI (1998) Development of a murine mutant Ras CD8+ CTL peptide epitope variant that possesses enhanced MHC class I binding and immunogenic properties. J Immunol 160:2433-2441

10. Britten CM, Gouttefangeas C, Welters MJ, Pawelec G, Koch S, Ottensmeier C, Mander A, Walter S, Paschen A, Muller-Berghaus J, Haas I, Mackensen A, Kollgaard T, Thor SP, Schmitt M, Giannopoulos K, Maier R, Veelken H, Bertinetti C, Konur A, Huber C,
Stevanovic S, Wolfel T, van der Burg SH (2008) The CIMT-monitoring panel: a two-step approach to harmonize the enumeration of antigen-specific CD8(+) T lymphocytes by structural and functional assays. Cancer Immunol Immunother 57:289-302

11. Clark EA, Golub TR, Lander ES, Hynes RO (2000) Genomic analysis of metastasis reveals an essential role for RhoC. Nature 406:532-535

12. Dalgleish AG, Whelan MA (2006) Cancer vaccines as a therapeutic modality: the long trek. Cancer Immunol Immunother 55:1025-1032

13. Hakem A, Sanchez-Sweatman O, You-Ten A, Duncan G, Wakeham A, Khokha R, Mak TW (2005) RhoC is dispensable for embryogenesis and tumor initiation but essential for metastasis. Genes Dev 19:1974-1979

14. Hanahan D, Weinberg RA (2000) The hallmarks of cancer. Cell 100:57-70

15. Kirkin AF, Reichert Petersen T, Olsen AC, Li L, thor Straten P, Zeuthen J (1995) Generation of human-melanoma specific T lymphocyte clones defining novel cytolytic targets with panels of newly established melanoma cell lines. Cancer Immunol Immunother 41:71-81

16. Kleer CG, Teknos TN, Islam M, Marcus B, Lee JS, Pan Q, Merajver SD (2006) RhoC GTPase expression as a potential marker of lymph node metastasis in squamous cell carcinomas of the head and neck. Clin Cancer Res 12:4485-4490

17. Kondo T, Sentani K, Oue N, Yoshida K, Nakayama H, Yasui W (2004) Expression of RHOC is associated with metastasis of gastric carcinomas. Pathobiology 71:19-25

18. Maecker B, Sherr DH, Vonderheide RH, Bergwelt-Baildon MS, Hirano N, Anderson KS, Xia Z, Butler MO, Wucherpfennig KW, O'Hara C, Cole G, Kwak SS, Ramstedt U, Tomlinson AJ, Chicz RM, Nadler LM, Schultze JL (2003) The shared tumor-associated antigen cytochrome P450 1B1 is recognized by specific cytotoxic T cells. Blood 102:3287-3294

19. Nestle FO, Alijagic S, Gilliet M, Sun Y, Grabbe S, Dummer R, Burg G, Schadendorf D (1998) Vaccination of melanoma patients with peptide- or tumor lysate-pulsed dendritic cells. Nat Med 4:328-332

20. Novellino L, Castelli C, Parmiani G (2004) A listing of human tumor antigens recognized by T cells: March 2004 update. Cancer Immunol Immunother 54:187-207

21. Pardoll DM (1998) Cancer vaccines. Nat Med 4:525-531

22. Pawelec G, Marsh SG (2006) ESTDAB: a collection of immunologically characterised melanoma cell lines and searchable databank. Cancer Immunol Immunother 55:623-627

23. Ridley AJ (2004) Rho proteins and cancer. Breast Cancer Res Treat 84:13-19

24. Rosenberg SA, Yang JC, Schwartzentruber DJ, Hwu P, Marincola FM, Topalian SL, Restifo NP, Dudley ME, Schwarz SL, Spiess PJ, Wunderlich JR, Parkhurst MR, Kawakami Y, Seipp CA, Einhorn JH, White DE (1998) Immunologic and therapeutic evaluation of a synthetic peptide vaccine for the treatment of patients with metastatic melanoma. Nat Med 4:321-327

25. Salgaller ML, Afshar A, Marincola FM, Rivoltini L, Kawakami Y, Rosenberg SA (1995) Recognition of multiple epitopes in the human melanoma antigen gp100 by peripheral blood lymphocytes stimulated in vitro with synthetic peptides. Cancer Res 55:49724979

26. Scheibenbogen C, Sun Y, Keilholz U, Song M, Stevanovic S, Asemissen AM, Nagorsen D, Thiel E, Rammensee HG, Schadendorf D (2002) Identification of known and novel immunogenic T-cell epitopes from tumor antigens recognized by peripheral blood $\mathrm{T}$ cells from patients responding to IL-2-based treatment. Int J Cancer 20(98):409-414

27. Schmidt SM, Schag K, Muller MR, Weck MM, Appel S, Kanz L, Grunebach F, Brossart P (2003) Survivin is a shared tumor- 
associated antigen expressed in a broad variety of malignancies and recognized by specific cytotoxic T cells. Blood 102:571-576

28. Sire J, Chimini G, Boretto J, Toubert A, Kahnperles B, Layet C, Sodoyer R, Lemonnier F, Jordan B (1988) Hybrid genes between Hla-A2 and Hla-A3 constructed by invivo recombination allow mapping of Hla-A2 and Hla-A3 polymorphic antigenic determinants. J Immunol 140:2422-2430

29. Sommerfeldt N, Beckhove P, Ge Y, Schutz F, Choi C, Bucur M, Domschke C, Sohn C, Schneeweis A, Rom J, Pollmann D, Leucht D, Vlodavsky I, Schirrmacher V (2006) Heparanase: a new metastasis-associated antigen recognized in breast cancer patients by spontaneously induced memory $\mathrm{T}$ lymphocytes. Cancer Res 66:7716-7723
30. Vieweg J, Jackson A (2004) Antigenic targets for renal cell carcinoma immunotherapy. Expert Opin Biol Ther 4:1791-1801

31. Vonderheide RH, Hahn WC, Schultze JL, Nadler LM (1999) The telomerase catalytic subunit is a widely expressed tumor-associated antigen recognized by cytotoxic $\mathrm{T}$ lymphocytes. Immunity 10:673-679

32. Wheeler AP, Ridley AJ (2004) Why three Rho proteins? RhoA, RhoB, RhoC, and cell motility. Exp Cell Res 301:43-49

33. Wu M, Wu ZF, Kumar-Sinha C, Chinnaiyan A, Merajver SD (2004) RhoC induces differential expression of genes involved in invasion and metastasis in MCF10A breast cells. Breast Cancer Res Treat 84:3-12 